\title{
Uncanny as Aesthetic Experience
}

\author{
Joo-eun Lee
}

Department of Digital Culture Contents, College of Liberal Arts, Konkuk University, Seoul, Korea

\section{심미적 경험으로서의 언캐니}

\author{
이 주 은 \\ 건국대학교 문과대학 문화콘텐츠학과
}

This paper interprets the work of Hans Bellmer, who took pictures after making a doll and distorting its form, and Diane Arbus, who took documentary photographs of unusual and marginalized people, as uncanny anxiety referred to by Freud. Through these two photographers' works, this paper examined how anxiety was used as an aesthetic strategy, and discussed the uncanny as an aesthetic experience. Uncanny refers to the phenomenon of familiar things being repressed and returning to their original place, or the phenomenon of familiarity being alienated due to repression. The aesthetic strategy of uncanny is used to bring a blind spot in reality that can be easily missed with an ordinary vision into the fore, by allowing for the slight shock to an appreciator. The ultimate goal of uncanny aesthetics is to promote both inner and external changes as well as to expand the scope of imagination, through freely crossing the borders between consciousness and unconsciousness, sympathy and antipathy, and reality and fiction.

Psychoanalysis 2017;28(3):69-75

KEY WORDS: Anxiety $\cdot$ Uncanny $\cdot$ Antipathy $\cdot$ Sympathy $\cdot$ Photograph.

Received: March 13, 2017 Revised: May 2, 2017 Accepted: June 12, 2017

Address for correspondence: Joo-eun Lee, PhD

Department of Digital Culture Contents, College of Liberal Arts, Konkuk University, 120 Neungdong-ro, Gwangjin-gu, Seoul 05029, Korea

Tel: +82-2-450-0435, E-mail: myjoolee@konkuk.ac.kr

\section{서 론}

철학자 Kierkegaard(1844)는 심리를 다룬 저서『불안의 개 념』에서 불안이란 반감적 공감, 혹은 공감적 반감이라고 정 의한 바 있다. 공감과 반감은 사물에 대해 감성적으로 개입 하는 것으로 심미적 경험에서 중요한 개념이다. 사람은 어떤 것에 두려움을 느끼면서도 그것을 갈망하기도 하는데, 이때 불안은 사람을 사로잡는 낯선 힘이라고 Kierkegaard(1844) 는 풀이한다. 이는 비록 실존적인 개념이기는 하지만, 정신 분석학적인 불안에도 적용될 수 있다. Freud(1919)가 논고 “Das Unheimliche"에서 제시한, 두려우면서도 그 안에 있는 어떤 익숙한 이끌림의 요소 때문에 완전히 떨쳐버리지 못하 는 음울하고 불안한 기분이 그것이다. 'Unheimlich'는 집 같 지 않다는 뜻으로, 영역본에서는 'uncanny'라고 번역되어 있

This is an Open Access article distributed under the terms of the Creative Commons Attribution Non-Commercial License (http://creativecommons.org/licenses/by-nc/4.0) which permits unrestricted non-commercial use, distribution, and reproduction in any medium, provided the original work is properly cited.
고, 우리말로 된 논문에서는 주로 ‘두려운 낯섦'이라고 바꾸 어 쓴다. 본고에서는 언캐니로 쓴다.

미학용어가 아님에도 언캐니는 초현실주의 미술작품을 위시로 하여, 오늘날 디지털 합성이미지에 이르기까지 광범 위하게 쓰이고 있고, 특수한 미적 경험을 지칭하는 용어로 자리 잡히고 있다. 그러나 언캐니한 불안이 감정의 단계에 그치지 않고 미적 경험으로 논의되기 위해서는 이미지의 어 떤 요소가 언캐니의 느낌을 유발하는지, 언캐니한 경험이 심 미적으로 지향하는 바는 무엇인지 정리가 필요하다.

Freud에 앞서 언캐니의 개념은 의학적인 심리학을 다루는 Jentsch(1906)의 논고에서 이미 다루어졌다. Jentsch(1906) 가 말하는 언캐니는 닮음과 모호함에서 야기된다. 언캐니는 겉보기에 익숙해서 쉽게 접근하게 되지만 명확하게 판단 내 릴 수 없는 부분을 마주하게 되고, 그로 인해 뜻 모를 불안감 에 휩싸이는 심리적 상황이다. Jentsch(1906)는 특히 인간을 닮은 대상들, 이를테면 밀랍인형이나 마네킹, 자동기계인형 을 예로 들면서, 꼭 생기가 있는 듯 보여서 혹시 영혼을 갖고 있지 않나 의심이 드는 경우라든가, 혹은 반대로 생기는 없 
지만 살아 있었던 것 같은 느낌이 드는 경우에 초점을 맞춘다.

반면 Freud(1919)가 강조하는 언캐니한 불안은 낮익음과 낯섦의 공존이다. 그는 독일어 'unheimlich'의 언어학적 유래 를 설명하면서, 집처럼 사적인 것을 표현하던 단어 'heimlich' 가 타인이 알지 못하게 비밀스럽다는 'geheimlich'의 의미까 지 포함하게 되고, 나중엔 그 은밀하던 것에 본인마저 낮설 게 되는 과정을 통해, 결국 'heimlich'한 것이 곧 'unheimlich' 하게도 되었다고 정리해준다. 다시 말해 '집처럼'이라는 단어 가 언어의 진화를 거쳐 이중의 의미를 가지게 되었는데, 그 하나는 낮익어 편안하다는 뜻이고, 다른 하나는 그 반대로 낮설고 불안하다는 뜻이다(Freud 1919).

Jentsch가 지적한 닮음과 모호함, 그리고 Freud가 언급한 낮익음과 낮섦의 양면성은 사진미학의 핵심이라고 할 수 있 다. 사진은 실물과 꼭 닮아서 낮익은 이미지이지만, 프레임 이라는 장치를 통해 전체에서 일부를 떼어 와서 보게 함으 로써 낮익은 장면을 낮설게 만든다. 사진은 장면을 실제맥락 으로부터 고립시킬 뿐 아니라, 시간의 흐름 속에서 이해되는 장면을 어느 한 지점에서 잘라 내어 멈춰진 순간으로 포착한 다. 한 장의 사진이미지가 실제로 무엇을 지시하는지는 정보 를 알려주는 제목이나 앞뒤로 연결된 이미지로 파악하기 전 까지는 모호할 때가 많다. 사진작가들은 네모라는 프레임과 절단된 시간이라는 속성을 가지고 닮음과 모호함, 그리고 낮 익음과 낮섦 사이를 넘나드는 미학적 기획을 구상하곤 한다.

사진을 정신분석학적으로 읽어 낸 대표적인 시도로는 미 술사학자 Krauss(1981)의 초현실주의 사진에 관한 연구를 들 수 있다. 사진이미지가 대상을 지시하는 지표(index)의 속 성을 갖는 이유는 그 지시물이 실제로 거기 있었다는 사실에 서 비롯되지만, 현실 속에서 사진이미지와 지시물이 늘 일치 하는 것은 아니다. 사진이미지는 견고하고 불변하지만 지시 물의 정체성은 맥락에 따라 흔들리고 분열되어 결코 그 이미 지의 영역에 머무르지 않기 때문이다. Krauss(1981)는 사진 이 지시성을 가지면서도 의미가 빗겨가는 것을 초현실주의 적이라고 해석하면서, 이를 정신분석적인 근거로 설명했다. 한편 시각문화연구자 Foster(1995)는 초현실의 개념을 정신 분석학적인 죽음충동과 언캐니의 힘이라는 틀로 해석하는 논문을 발표하기도 했다. 그는 초현실주의에서 강조하는 '우 연한 발견'이 마치 미리 정해져 있던 것의 반복이라던가 혹 은 되찾아지는 것이 아닌데도 되찾는 듯 느껴지는 어떤 것임 을 지적하면서, 그것을 억압된 것이 회귀하는 언캐니의 힘과 연관 지었다. 그 외에도 Sievers(2008)는 보이지 않는 시각성 이나 생각하지 못한 앎의 영역, 즉 무의식에 접근하고 이해 하기 위한 도구로 사진이미지를 활용하는 방법과 그 효과에 대해 연구한 바 있다.
초현실주의 사진이 아닐지라도 대부분의 사진이미지는 언캐니의 영역에 있다. 카메라에는 평범한 사건을 평범하지 않게 보이도록 만드는 힘이 있기 때문이다. 그러나 사진가 자신이 언캐니한 경험으로 대상에 접근하고 그것을 토대로 작품을 표현하여 미적으로 승화시킨 사례는 많지 않다.

본고는 인형을 만들어 형태를 왜곡시킨 후 사진을 찍은 Hans Bellmer(1902 1975)의 작품과 특이하고 소외된 부류 의 사람들을 다큐멘터리 사진으로 남긴 Diane Arbus(1923 1971)의 작품을 언캐니한 불안의 개념으로 해석하고자 한다. 이 두 작가의 사진작품을 통해 불안감이 어떤 방식으로 미 학적 전략으로 활용되는지 살펴보고, 심미적 경험으로서의 언캐니에 대해 논의해 볼 것이다.

\section{본 론}

\section{유사존재 속에 잠재한 공포}

Bellmer는 현재는 폴란드이지만 옛 독일령이던 지역에서 태어났다. 그가 인형 프로젝트를 시작한 공식적인 이유는 나 치당의 파시즘에 반항하는 의미로, 자신은 나치를 지지하는 일은 절대로 하지 않겠다는 의지의 표명이었다. 심신단련을 통해 강철같이 강건한 신체와 건전한 정신을 갖는 것이 새 제국건설의 기초라고 나치당이 외치고 있을 때, Bellmer가 내놓은 인형은 Figure 1에서 보듯 수족이 잘리거나 뒤틀려 꺾이고, 기괴하게 하반신과 상반신이 맞붙어 있는 형상이었 다. 그는 인형을 만들어 사진작업을 했는데, 이 사진집은 나 치의 검열에 의해 '퇴행적(degenerate)'인 예술이라는 낙인을 받았다. 그 사건을 계기로 그는 사진집을 들고 파리로 망명 하여 초현실주의자들과 만나게 된다.

거슬러 올라가 Bellmer의 반항적인 인형 작업은 그의 개

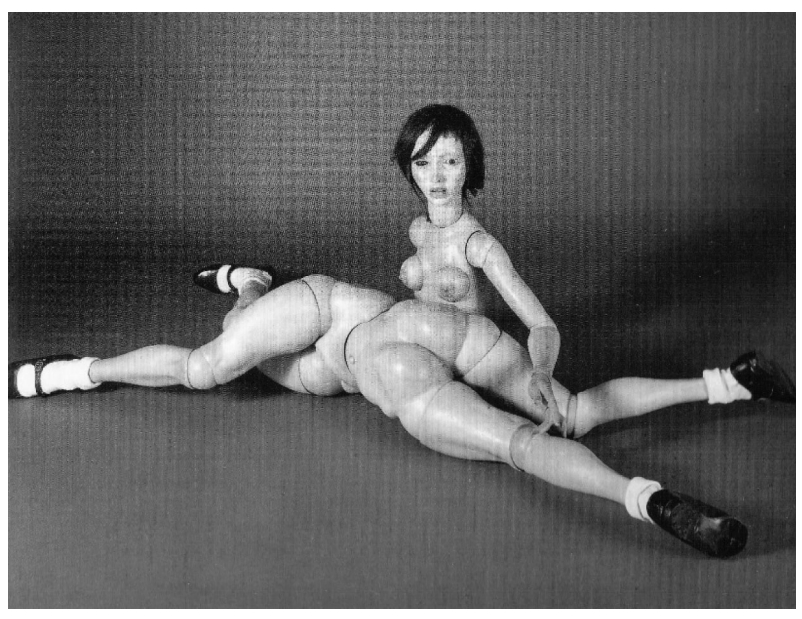

Figure 1. Hans Bellmer, 'The Doll', 1932-1945 (painted wood, hair, shoes, socks, $61 \times 170 \times 51 \mathrm{~cm}$, Centre Georges Pompidou, Paris). 
인사와 관련이 있다. 그의 아버지는 유머라고는 전혀 없는 권위적인 사람이었고, 가족에게 맹종을 요구했다. Bellmer의 잔인한 인형학대 작업은, 소아정신분석학자인 Klein(1932) 이 지적하였듯, 아버지의 강압적 권위에 대한 분노의 표현이 라고 이해해 볼 수 있다. 생물학적 아버지에 대한 어린 시절 의 분노가 인간의 자유를 통제하고 욕망을 억압하는 경찰, 파시즘, 국가라는 상징적인 아버지로까지 확장된 것이다.

서른 살이던 1932년에 그는 십대의 어린 사촌 여동생에 대 해 이룰 수 없는 애정을 품고, 금지된 욕망으로 인해 괴로워 하게 된다. 마침 이 무렵 자동기계인형과 사랑에 빠진 주인 공이 나오는 「호프만 이야기」를 오페라로 보게 되었고, 이것 에서 영감을 받아 1933 년에 처음으로 실물 크기의 인형을 제 작하였다. 그가 만든 모든 인형은 소녀의 모습을 하고 있으 며, 기계인형의 느낌을 주듯 관절부분이 자유자재로 돌아가 는 구체관절 형태를 띠고 있다. 이는 사촌여동생 이미지와 자동기계인형 이미지가 합해진 결과라고 이해할 수 있다.

언캐니에 대한 Jentsch(1906)의 논고에서도 자동기계인형 이 예시로 등장한다. 올림피아는 오페라 「호프만 이야기」의 원작인 Hoffmann(1816)의 환상소설『모래사나이』에 나오는 인형으로, 주인공 나타니엘의 분신과도 같은 존재이다. 나타 니엘은 멀리서 올림피아를 바라보면서 사랑의 감정을 키우 지만, 정작 그녀의 기계손을 만졌을 때 소름이 끼치고, 얼음 같은 그녀의 입술에 키스하는 순간 깊은 공포에 휩싸이게 되며, 욕망이 좌절되고 만다. 이 순간을 옌치는 언캐니하다 고 본 것이다.

살아 있음과 죽음에 대한 지적 불확실성이 곧 두려운 낯섦 을 유발하는 원인이라고 주장하는 Jentsch(1906)의 글에 대 해 Freud(1919)는 다른 관점으로 논지를 편다. "모래사나이』 의 이야기에서 핵심이 되는 것은 인간을 닮은 인형이 아니라, 잠들지 못한 아이들의 눈을 빼간다는 '모래사나이’라는 보이 지 않는 존재라는 것이다. 모래사나이의 이야기를 듣고 자라 난 어린 나타니엘은 그에게 눈을 빼앗길지도 모른다는 공포 를 갖게 되고, 이 망상은 현실 속에서 분신 올림피아를 통해 묘하게 실현된다.

소설의 결말 부분에서 작가 Hoffmann(1816)은 올림피아 의 눈을 뺀 노인이 곧 나타니엘의 아버지를 죽인 남자와 동 일인물이고, 궁극적으로 그가 바로 오래된 공포의 근원인 모 래사나이의 실체였다는 것을 일러준다. 여기서 Freud(1919) 는 인형이 인간과 유사한 존재라는 이유만으로 언캐니하지 는 않다고 지적하면서, "어둠 속에 비밀로 남아 있어야 하는 것'과 '어둠 속에서 나온 것'에 주목한다. 다시 말해 억압된 공포가 회귀하는 것, 그리고 허구와 사실의 경계가 사라지는 오컬트한(occult) 상황, 그리고 분신을 통한 정체성의 이중현
상 등이 언캐니의 감정을 유발하는 요인들이라는 것이다 (Freud 1919).

요컨대, 언캐니한 감정은 직선적인 시간의 흐름 속에서 순 차적으로 진행되는 불안이 아니라, 기분 나쁘고 충격적인 경 험이 도돌이표처럼 반복되고 있다는 사실을 느끼는 것에서 비롯되는 반복강박의 일환이라고 볼 수 있다(Freud 1920). 실제로 충격이 되풀이된 상황에서 겪게 될 큰 두려움을 완 화시키기 위해 자기보호 차원의 작은 불안감들이 조성되는 데, 그것이 바로 언캐니한 기분을 유발하는 것이다. 이는 억 압된 것의 특성들 중 하나로도 볼 수 있으며, 과거에 익숙하 던 유아적 콤플렉스의 재생이라고 추적될 수도 있다.

Bellmer는 Figure 2에서 미완성 상태로 작업실 계단에 내 팽개쳐진 인형 혹은 장난감처럼 비틀리다가 버림받은 인형 이 마치 우리를 원망하듯 쳐다보는 순간을 사진으로 포착했 다. 사진이미지는 거리 두기 효과를 내면서 망가진 인형의 모습을 하나의 사건처럼 객관화한다. Figure 3은 언뜻 사건 의 현장처럼 보이는데, 자신이 저지른 잔혹한 행동들을 기록 해 둔 연쇄살인자의 사진을 보는 듯 섬뜩하다. Bellmer는 결 혼 후부터는 인형학대 작업을 그만두지만 인형 대신 그의 아 내가 자살로 생을 마감했다. 허구 속의 인형과 현실 속의 아 내가 마치 억압된 과거가 되돌아오는 예측된 미래인양 맞물 려서 언캐니를 느끼게 한다.

인형은 마음대로 할 수 있는 수동적인 사물이지만 지나치

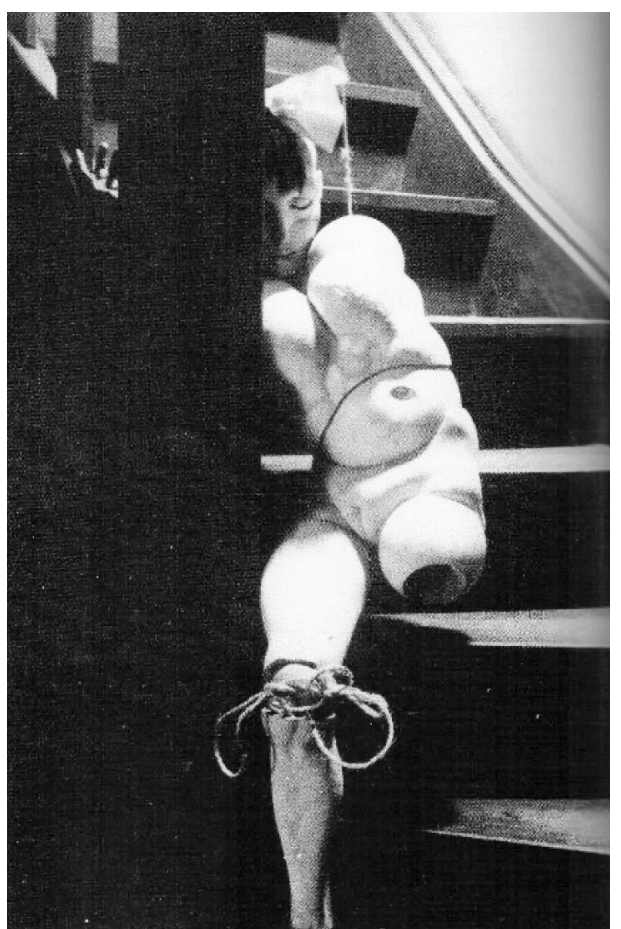

Figure 2. Hans Bellmer, 'The Doll', 1936 (hand-colored gelatin silver print, $73.7 \times 50.8 \mathrm{~cm}$, Herbert Lust Gallery). 


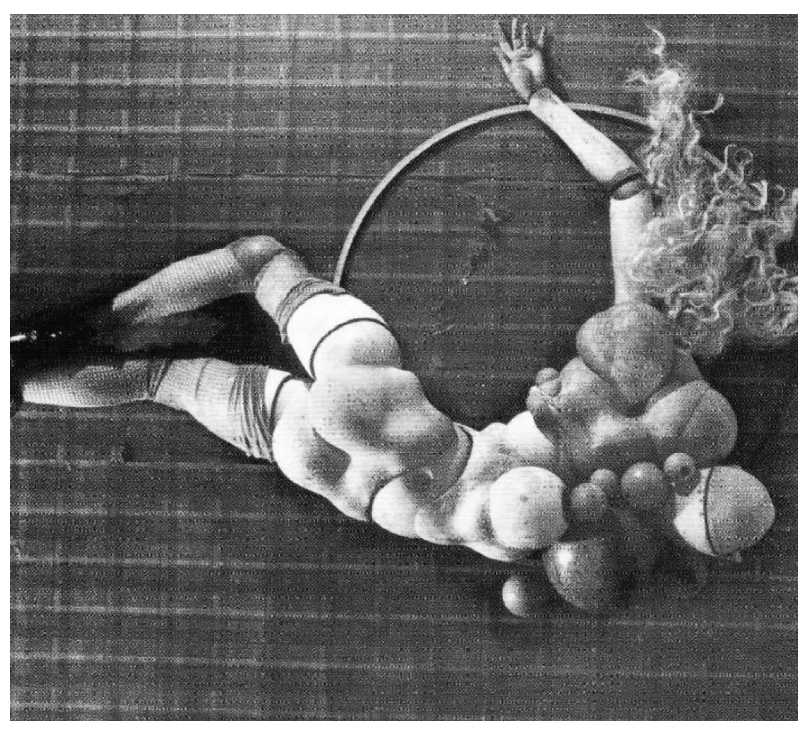

Figure 3. Hans Bellmer, 'The Doll', 1935 (hand-colored gelatin silver print on original stretcher, $66 \times 66 \mathrm{~cm}$, Ubu Gallery, New York, and Galerie Berinson, Berlin).

게 사람과 유사하기 때문에 사람이 세상에 부여한 질서를 깨 뜨리고 예기치 않은 공격을 할 것 같은 환상을 자아낸다. 이 러한 이중성으로 인해 인형 모티프는 가장 억압된 것이 곧 가장 전복적인 것일 수 있다는 잠재성을 표현하기에 효과적 이다. 그러나 닮은 외양에서 오는 공포의 의미가 Bellmer 작 품의 전부는 아니다. 그의 작품 속에서 인형 모티프는 세 가 지 목적으로 활용된다. 첫째, 피그말리온의 피조물처럼 인형 에게 인간의 욕망을 투사시키는 페티시즘적인 것, 둘째, 자 신의 분신인양 인형에게 가혹하게 상처를 입힘으로써 사회 속에서 고통받는 자아를 표현하는 것이다(Foster 2002). 셋 째는 언캐니한 상황으로, 능동적으로 변한 인형이 프랑켄슈 타인의 피조물처럼 흥측한 괴물이 되어 창조자인 인간을 원 망하는 것이다.

조각가로서의 Bellmer는 피그말리온처럼 애정을 가지고 인형에 유리눈알을 넣고 가슴의 유두와 성기의 표현까지 정 밀하게 묘사했으며, 옷이나 구두 같은 현실의 물건들로 장식 하여, 흡사 살아 있는 인간처럼 느끼도록 만들었다. 그러나 사 진가로서의 Bellmer가 이미지화한 것은 생명 없이 차가운 절 단된 시신 같은 몸이다. 뒤틀린 인형의 몸체는 파편으로 분해 되었고, 해부학적인 원리에 맞지 않게 조합되었다. 해체된 인 형은 인간이 아니라 마치 조립 가능한 기계부품과 다름없어 보인다. 조각작품으로서의 인형의 몸이 촉각적이라면, 사진 은 그 몸에서 촉각적인 기억을 없애고 서늘하고 낮선 구경거 리 대상으로 재탄생시킨다. 한때는 사랑받았었고 욕망이 깃 들어 있었던 몸이었기에 더욱 언캐니하게 여겨진다.

인간과 기계, 욕망과 죽음의 속성이 역설적으로 공존하는
이미지를 통해 Bellmer의 인형은 금기된 성애를 자극하는 유혹적인 존재이면서 동시에 권력에 의해 희생되는 수동적 인 존재라는 이중적인 메시지를 던진다. Bellmer의 작품에는 공포의 감정이 깔려 있는데, 작가는 이를 고유한 방식으로 미 적 경험으로 치환시킨다. 그는 인형이 가진 객관적 사물로서 의 속성을 강조하는 동시에 인간과 닮은 외양에서 비롯되는 주관적 감정이 환기되도록 의도하면서, 이 두 상반된 측면이 끓임없이 교차하는 상황을 유도하였다. 이러한 미학적 기획 을 통해 Bellmer의 인형작품은 파시즘이 전횡하던 시절에 기계적인 권력체제에 의해 억압되고 좌절된 인간의 욕망을 표상할 수 있었던 것이다.

\section{이질감과 동질감 사이의 긴장}

Arbus는 스스로 회상하기를, 지독히도 수줍음이 많은 아 이였다고 한다. 부유한 집안의 순종적인 딸로 자라났고 아름 다운 외모를 지녔으며, 결혼 후에는 두 딸을 키우는 가정의 여주인으로 지냈다. 그러나 사진작가로서의 그녀에겐 기괴 한 사진을 일부러 찍으러 다니는, 금기를 즐기는 스릴 중독 자라는 꼬리표가 붙어 있다. 그녀가 피사체로 삼은 인물은 지 극히 일상적이고 사적인 공간에 있는 기형인, 성전환자, 양성 보유자, 정신지체인, 나체주의자 등이었다. 1960년대 당시 그들의 이미지는 기이한 쇼(Freak Show)에서나 볼 수 있었 고, 더욱이 여자가 그런 사진을 찍으러 돌아다닌다는 것은 용납조차 어려웠을 것이다.

Arbus는 촬영을 할 때 피사체가 자연스럽게 스스로를 연 출할 수 있도록 도왔다. 인터뷰를 기록한 사진집에서 그녀는 이렇게 말한다. "거부감이 작업의 출발점이에요. 하지만 그걸 바꾸려 들지 않아요. 대신 나 스스로를 적응시킵니다"(Arbus 2011). Figure 4는 멕시코인 난쟁이 모랄레스를 촬영한 사진 이다. Arbus는 모랄레스의 사진을 찍기 전에 먼저 그에게 접 근하여 친해져야 했고, 거리감 없는 소통을 목적으로 종종 성관계까지 갖기도 했다(Bosworth 1984). 그들의 육체적 친 밀함은 모랄레스가 은밀한 장소인 침대 위에서 옷을 모두 벗은 채 수건으로 하반신을 가리고 Arbus의 카메라 앞에 자 연스럽게 앉아 있는 상황에서 짐작할 수 있다.

보통신체의 남자가 침대에서 반라의 포즈를 취하고 있다 면, 감상자는 제일 먼저 관능적 유혹의 분위기를 연상할 것 이다. 하지만 모랄레스의 경우라면 짧은 수족에 먼저 신경이 쓰이게 된다. Arbus가 지적하듯 신체적 약점이 있는 사람은 어떤 맥락에 가져다 놓아도 오직 약점만 부각되기 때문이다 (Arbus 2011). 약점이란 낙인과도 같이 몸 전체를 규정짓고 맥락의 전부를 장악한다. 모랄레스의 사진에서 관능성은 화 면에 노골적으로 제시되어 있음에도 불구하고 철저히 억압 


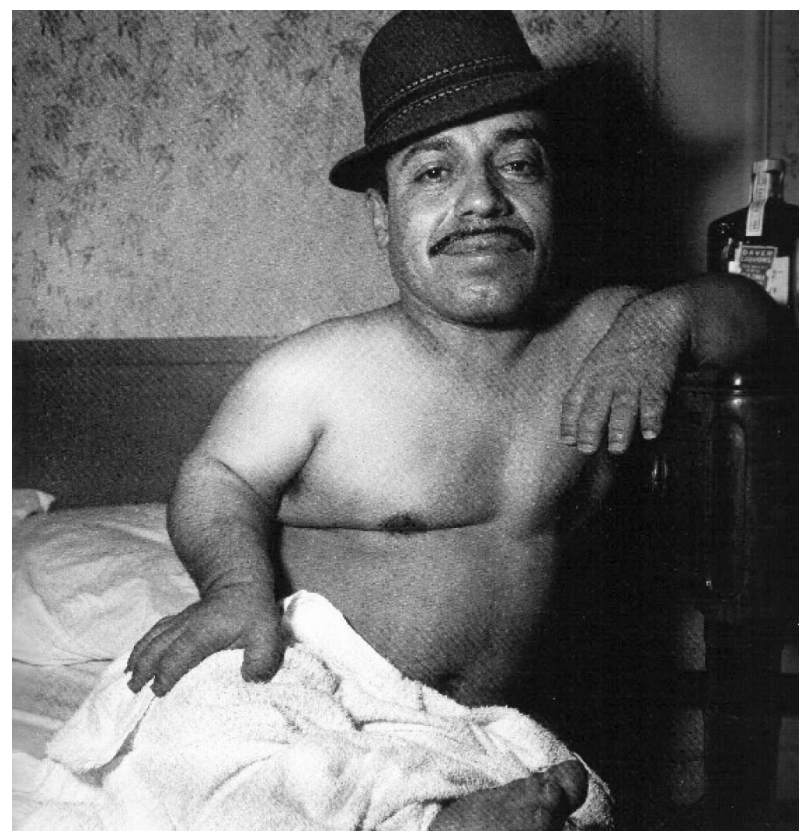

Figure 4. Diane Arbus, 'Mexican Dwarf in his Hotel Room in N.Y.C.', 1970 (gelatin silver print, $36.8 \times 36.2 \mathrm{~cm}$. Courtesy of Diane Arbus Foundation).

되고 은닉되어 있다.

Freud(1919)는 'heimlich'한 것을 'unheimlich'하게 느끼는 것은 익숙함을 억압한 결과이며, 이때 접두사 'un’이 바로 억 압의 징표라고 언급한다. ‘Unheimlich’는 집인데도 집처럼 느 껴지지 않을 때를 일컫는다. 겉으로 드러난 집의 이면에는 억 압되고 감추어진 한 겹의 무엇이 더 있는 것이다. 낮익은 것 이 억압을 거쳤다가 제자리로 되돌아오는 현상, 또는 억압으 로 인해 익숙함이 소외되는 현상이 바로 언캐니이다(Freud 1919).

Figure 5는 나체캠프에서 만난 부부의 모습인데, 이 사진 을 찍을 때는 Arbus도 나체로 지냈다. 심신이 모든 규율에서 해방되어 절대자유를 누리리라는 Arbus의 기대와는 달리, 나체캠프 내의 규율은 엄격했고 이 캠프에 온 사람들의 성 향은 옷을 껴입은 사람들보다 몇 배 더 금욕적이었다. 발기 가 된 남자는 무조건 추방되었고, 누군가의 몸을 쳐다보면 당장 경고조치가 내려졌다(Arbus 2011). 이들은 몸 어딘가에 성욕을 감춰 둘 수가 없었다. 눈을 뜨고 있지만, 그 누구도 상 대의 알몸을 보지 않았고, 옷을 벗었지만 모두 암묵적으로 옷을 입은 듯 행동했다. 집인데도 집이 아닌 듯 느껴지는 언 캐니의 의미처럼, Arbus가 사진으로 보여주는 이 부부는 나 체이지만 결코 나체처럼 여겨지지 않는 사람들이었다.

1970년에 Arbus는 뉴저지에 있는 지적 장애자들의 주거 지를 촬영했는데, Figure 6이 그중 한 장면이다. 중년의 지적 장애자 두 명이 마치 학교파티를 위해 차려 입은 소녀들처

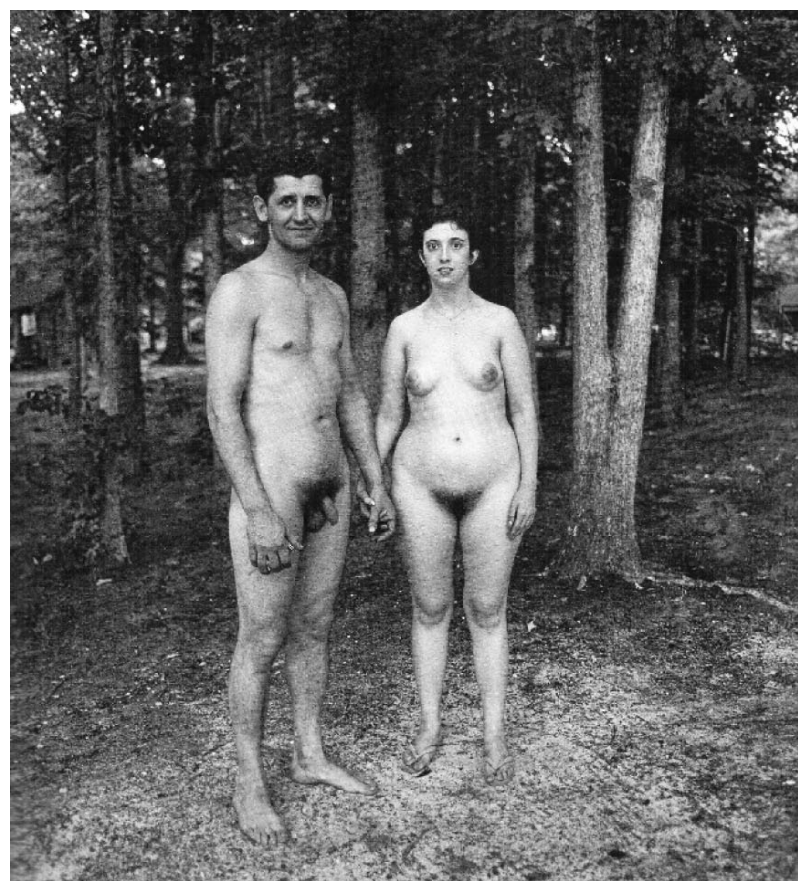

Figure 5. Diane Arbus, 'A Husband and Wife in the Woods at a Nudist Camp', N.J., 1963 (gelatin silver print, $36.8 \times 36.5 \mathrm{~cm}$, Courtesy of Diane Arbus Foundation).

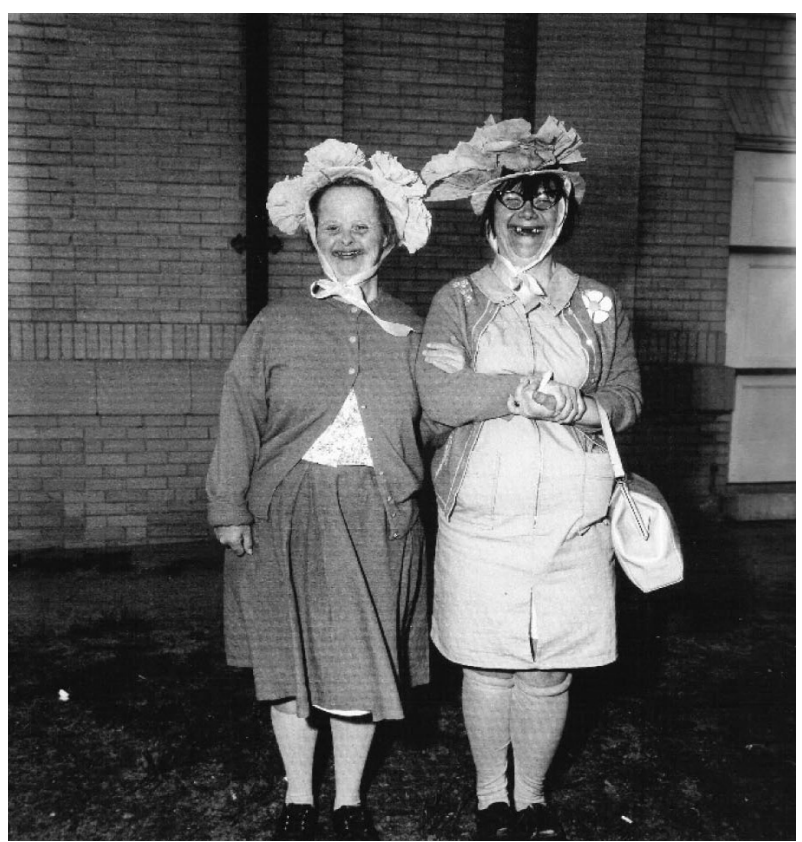

Figure 6. Diane Arbus, 'Untitled (I)', 1970-1971 (gelatin silver print, $36.8 \times 36,8 \mathrm{~cm}$, Courtesy of Diane Arbus Foundation).

럼 서 있다. 이들은 카메라를 든 Arbus의 존재를 의식하지 않았고 혼자만의 공간에서도 달라진 행동을 보이지 않았다. 베일에 가려진 인물들의 사적인 공간을 찍는 프로젝트에서 Arbus는 매번 그들의 은밀한 일상을 노출시킴으로써, 피사 체에게 감상자가 예상하지 못하는 다른 세계도 있다는 것을 
보여주려고 했다(Sontag 1977). 피사체의 낮선 이미지를 친 숙한 이미지로 급전환시킴으로써 엄청 놀랍지는 않지만 어 딘가 어울리지 않는다고 느끼게 하는 것이 사진작업의 목적 이었다. 이를 위해 Arbus는 스스로를 던져 피사체와 일체감 을 이루었고, 그 점에 있어 가히 천재적이었다. 그런데 지적 장애자들과의 관계에서는 그 재능을 발휘할 방법을 찾지 못 했던 듯하다.

자의식이 결여된 지적 장애자들은 베일을 걷어 낸다 해도 또 다시 알 수 없는 베일이 드리워져 있었기에, Arbus의 카 메라조차 결코 이면의 진실에 다가설 수 없었다. 어쩌면 이 들에겐 정말로 드러낼 수 있는 진실, 즉 정체성 자체가 부재 하는지도 모른다. 지적 장애자들을 찍은 사진은 피사체는 있 지만, 피사체가 지시하는 바는 공허하게 비어 있는 언캐니한 이미지인 셈이다. 촬영을 마친 후 Arbus는 갑작스레 자살했 는데, 장애자들의 사진에는 아무런 제목도 붙이지 않은 채였 다. 사진가의 원인을 알 수 없는 자살과 더불어 피사체에 대 한 정보가 나타나지 않는 무제의 사진들은 사진 속 이미지 의 비밀스러움과 기괴함을 증폭시킨다.

사진이미지는 어떤 방식으로든 사진가의 경험에 형태를 부여한다. Arbus는 때로는 카메라를 든 냉정한 관찰자였지만 때로는 피사체들처럼 그녀 자신도 소외된 인간이었다. 그녀 는 어디에 속한 자신이 진짜 자신인지 종종 혼란스러워했고, 그 혼란은 피사체에 대한 이질감과 동질감이 뒤섞이는 상태 에서 비롯되는 언캐니한 불안이었을 것이다. Arbus는 직접 본 적 없는 환상 속에나 존재할 것 같은 인물을 일상적 맥락 에 위치시키는 전략으로 어딘지 모르게 부적절해 보이는 이 미지를 제시했다. 그녀가 찍은 사진을 보며 감상자가 이상하 다고 느낀다면 그 이유는 피사체에 대해 갖고 있는 무의지적 인 거부감 때문일 것이다. Arbus의 사진이미지들은 상이한 요소들이 공존하는 언캐니의 미학을 실현하면서, 그것을 통 해 사회적 편견의 문제를 예리하게 가시화할 수 있었다.

\section{결 론}

낮익으면서도 낮설어서 한편으로는 이끌리면서도 다른 한 편으로는 두려운 양가적(ambivalent) 감정인 언캐니는 불안 의 원인이면서 동시에 심미적 경험에 잠재하는 속성 중 하나 라고 볼 수 있다. 특히 사진이미지는 실물과 정확하게 닮아 실물을 대신할 수 있을 듯 하지만, 알고 보면 실체가 부재하 는 허상에 불과하기 때문에, 언캐니한 경험을 논하기에 적절 한 예술장르이다. 본고에서는 학대받은 인형과 소외되고 격 리된 인간을 찍은 사진이미지를 살펴보면서 언캐니의 바탕 이 되는 억압의 요소와 어둡고 비밀스러운 본성을 다루었다.
언캐니의 개념은 일찍이 로봇제품에 대한 호감도 연구에 활용된 바 있다. 1970년에 일본의 로봇 공학자, 모리 마사히 로는 차가운 느낌의 로봇 제품을 출시할 때 사용자에게 호감 을 높이는 방법으로 기계에 인간을 닮은 이미지를 입히는 것 을 제안하였다. 그는 로봇이 인간을 닮는 정도가 상승함에 따 라 사람들의 호감도도 함께 높아지다가 어느 순간 섬뜩해지 는 느낌으로 넘어서게 된다는 것을 발견했다. 이 순간이 바로 닮음이 낮섦으로 전환되며 호감도가 급속 하강하는 언캐니 밸리(uncanny valley) 그래프의 변곡점이다(Chin 2014).

최근에 언캐니 밸리 이론을 미적 경험으로 재해석할 여지 를 남긴 사람이 있는데 핸슨 로보틱스의 설립자 David Hanson이다. Hanson(2005)은 바로 이 섬뜩한 순간이 디자인만 잘 된다면 오히려 '참여의 통로(path of engagement)'가 되어 사용자를 제품에 적극 끌어들일 수 있다는 것을 실험을 통해 밝혀냈다. 마사히로의 경우는 인간을 닮은 로봇의 겉모습이 호감도에 결정적이라고 주장했지만, Hanson(2005)은 닮은 외양 자체에만 치중하지 않았다. 로봇의 생김이 비록 섬뜩하 다 할지라도 그것에 인터랙션과 같이 강력하게 시선을 사로 잡고 미학적으로 흥미를 끌만한 다른 요소가 있다면, 사람들 은 언캐니밸리의 구간을 쉽게 넘어설 수 있다는 것이었다. 물 론 이때 언캐니한 불안감이 참여의 통로로 바뀌도록 미적으 로 기획하는 것은 예술가의 몫이다.

아름다움은 조화와 분명함을 속성으로 하는 대상에서 주 로 경험되지만 언캐니적인 아름다움은 부조화와 불명료한 대상에 의해 촉발되는 특수한 경험이다. 거기에는 약간의 공 포가 수반되지만, 공포 자체가 미학적 목표는 아니다. 언캐 니의 전략은 감상자를 알 수 없는 공포에 노출시킴으로써, 평이한 시각으로는 놓치기 쉬운 현실 속의 사각지대를 시야 에 들추어 내기 위해 이용된다. 공포는 인간이 지닌 원초적 인 정서이면서 저항할 수 없는 강렬한 힘이므로, 공포를 작 품에 끌어들이는 것은 감상자에게 충격을 주어 참여의 통로 를 만드는 효과적인 방법이다.

무엇보다 언캐니의 미학은 과거-현재-미래로 이어지는 순차적인 시간성을 벗어나, 과거와 미래를 한꺼번에 품은 비 대해진 현재라는 특수한 시간성의 경험에서 발생한다. 그 경 험은 결정과 미정, 벌어짐과 벌어지지 않음 사이의 모호함에 서 발생하는 것으로, 거부감과 호감 사이의 미결정 상태에서 오는 긴장감이자, 일이 벌어질지 모른다는 기대와 초조함에 서 일어나는 쾌(快)의 경험이기도 하다. 작품의 의미가 정해 지지 않기 때문에, 언캐니한 이미지는 어느 하나의 의미에 귀 착하지 않은 채 계속해서 부유하는 현재진행형으로 존재한 다. 그것은 감상자와 작품 사이에서 일어나는 지금 이 순간의 경험과 의미발생을 중시한다. 
세상에는 하나의 범주로 표현하기 어렵고, 하나의 경계 내 에서 이해될 수 없는 신비로운 것이 있다. 그런 것은 이분법 적인 사고의 틀을 벗어나거나 넘어서 있기에 미적 확신을 주 지는 못하지만, 끊임없이 이끌림과 호기심을 유발하게 하므 로 엄청난 예술적 생명력을 가지고 있다. 언캐니한 이미지는 의식과 무의식, 사실과 허구, 억압된 과거와 그것이 회귀할 미래 등이 양립하며 교차하는 심리적 상태와 관련되어 있다. 이질적인 영역 사이의 자유로운 경계 넘음을 통해 상상력의 지평을 확장시키면서 내적이고 외적인 변화를 도모하는 것 이 언캐니 미학의 궁극적인 지향점일 것이다.

\section{Acknowledgments}

This research was partially inspired by Soo Yeun Choi's master's thesis on Diane Arbus.

\section{Conflicts of Interest}

The author has no financial conflicts of interest.

\section{REFERENCES}

Arbus D. Notes. In: Israel M, Arbus D. Diane Arbus: an Aperture Monograph. Diane Arbus fortieth-anniversary edition catalogue. Millerton, NY: Aperture Foundation;2011. p.1-15.

Bosworth P. Diane Arbus: A Biography. New York: Avon Books;1984.
Chin JK. Image Humanities 2. Seoul: Imagine1000;2014. p.91-102.

Foster H. Compulsive Beauty. Cambridge, MA: MIT Press;1995.

Foster H. Violation and Veiling in Surrealist Figuregraphy: Woman as Fetish, As Shattered Object, as Phallus. In: Mundy J. Surrealism: desire unbound. New Jersey: Princeton University Press;2002. p.208215.

Freud S. Das Unheimliche (1919). In: The Standard Edition of the Complete Psychological Works of Sigmund Freud vol. 17. London: Hogarth Press;1974. p.224-225, 244-245, 247-249.

Freud S. Jenseits des Lustprinzips (1920). In: The Standard Edition of the Complete Psychological Works of Sigmund Freud vol. 18. London: Hogarth Press; 1974.

Hanson D. Expanding the Aesthetic Possibilities for Humanoid Robots. In: Proc. IEEE Humanoid Robotics Conference, special session on the Uncanny Valley. 2005 Dec; Tskuba, Japan: 2005.

Hoffmann ETA. Sand Man (1816). In: The Sandman. Montana: Kessinger Publishing LLC;2010.

Jentsch E. Zur Psychologie des Unheimlichen. Psychatrisch-Neurologische Wochenschrift;1906. p.195-205.

Kierkegaard S. Begrebet Angest (1844). In: The Concept of Anxiety in Soren Kierkegaard. Atlanta: Mercer University Press;2008.

Klein M. The Psycho-Analysis of Children. London: Hogarth;1932.

Krauss R. Figuregraphic Conditions of Surrealism. October, MIT Press, vol.19, Winter, 1981. In: The Originality of the Avant-garde and Other Modernist Myths. Cambridge: MIT Press;1994. p.87-118.

Sievers B. Perhaps it is the role of pictures to get in contact with the uncanny: the social Figure matrix as a method to promote the understanding of the unconscious in organizations. Organ Soc Dyn 2008;8:234-254.

Sontag S. On Figuregraphy. New York: Farrar, Straus and Girous;1977. 